\title{
Fuzzy Roughness Measurement Model Based on Membership Effect
}

\author{
Fa-Chao Li \\ Hebei University of Science and Technology, No. 26 \\ Yuxiang Street, Shijiazhuang 050018, P. R.China \\ lifachao@tsinghua.org.cn
}

\author{
Li-Kun Wang \\ Hebei University of Science and Technology, No. 26 \\ Yuxiang Street, Shijiazhuang 050018, P. R.China \\ 591716508@qq.com
}

\begin{abstract}
Rough fuzzy set theory and fuzzy set theory are two commonly used tools in today's uncertain type of information processing. How to construct a fusion method for two kinds of uncertain information systematically has been a focus in both academic and applied fields. By analyzing the characteristics and shortcomings of the current fuzzy roughness sets, this paper puts forward concept of membership effect function and establishes a fuzzy roughness measurement model based on membership effect (denoted by FRM-BME, for short). And then, several necessary and sufficient conditions are given to reflect the value of FRM-BME. Finally, we propose an attribute reduction algorithm based on FRM-BME, and further analyze the characteristics and effectiveness of FRMBME combined with specific cases. Theoretical analysis and experimental results show that, FRM-BME not only has good structural characteristics and interpretability, but also can simply integrate the fuzzy processing preference into roughness measurement system. To a certain extent, it not only enriches the existing related theories, but also can be widely used in artificial intelligence, resource management and many other fields.
\end{abstract}

Keywords-Fuzzy set; Roughness; Fuzzy rough set; Membership effect function; Attribute reduction

\section{INTRODUCTION}

Rough set theory is proposed by Pawlak [1] in 1984, it's basic idea is to use a partition (knowledge) of domain to consider the description problems of the concept on domain. It is a theoretical tool to seek a complete conclusion using incomplete information. Due to the substantive characteristics of rough set and data mining are very consistent, many scholars conducted a number of meaningful discussions combine with different theoretical and practical background. At the meantime, they have gained many important theoretical and practical achievements. For example, Slowinski [2] put forward the rough set model based on similarity relation; he used a similar relationship instead of equivalence relationship in Pawlak rough set model.

Because of the knowledge or concepts in Pawlak rough set models is clear, but not in practical problems, and it always have fuzziness, so many scholars had promotion this model aimed at the problem of integration of fuzziness and roughness. Among them, for example, Dai and Tian [3] constructed a fuzzy rough set model for set-valued information systems; Qian and Wang [4] proposed an accelerator, called forward approximation, which combines sample reduction and dimensionality reduction together, can be used to accelerate a heuristic process of fuzzy-rough feature selection; Jia and Shang [5] focused on the problem of how to choose or define appropriate reducts for different users in different applications; Shu and Shen et al. [6] proposed an incremental feature selection method which can accelerate the feature selection process in dynamic incomplete data; Li and Zhang et al. [7] proposed an attribute importance measure based on the change rate of knowledge, and established a multi-attribute decision model combined with fuzzy integral; Neil and Richard [8] presented two different approaches for unsupervised feature selection, both of approaches use fuzzy-rough sets to select features for inclusion or removal from the final candidate subset. By introducing the notion of fuzzy $\beta$-minimal description, Yang [9] defined a novel type of fuzzy covering-based rough set model and generalized this model over the fuzzy lattice.

Because of the rough fuzzy set and fuzzy rough set are both comprehensively uncertain descriptive methods involving fuzziness and roughness, and they are the foundation of many complex decision-making problems, so it has great value in both theory and application to figure out how to construct the system with structural features of the fuzzy rough measure method. But it is worth noting that the current study is lack of considering the effect of membership on rough measure mechanism, and these are issues what we must to be faced when we work on fuzzy rough decision. In this paper, we have the following aspects: 1) We analyze the shortcomings of Pawlak roughness measure model with specific examples. 2) We analyze of the functional characteristics of membership, as well as the concept of membership effect function. 3) We construct fuzzy roughness measure model based on membership effect, and analyze the features of the FRM-BME. 4) With case, we analyze the features of FRM-BME by examples.

\section{FEATURE ANALYSIS OF CURRENT ROUGHNESS MEASURE METHODS}

This thesis uses the $U$ to represent a non-doctrinaire universe, and agrees that: 1) $F(U)$ is the representation of whole fuzzy sets (mapping from $U$ to $[0,1]$ ) above $U$, and $\mathrm{P}(\mathrm{U})$ is the representation of whole Cantor set on $\mathrm{U}$; 2) For $A \in \mathrm{F}(\mathrm{U}) \mathrm{A}(\mathrm{x})$ means the membership function of A; 3) $\mathrm{R}$ is the equivalence relation of $\mathrm{U}$ (i.e. $R \subset U \times U$ and meets: i) $(x, x) \in R$ is on any permanent establishment; ii) when $(x, y) \in R$, there will be $(y, x) \in R$; iii) when 
$(x, y) \in R,(y, z) \in R$, there will be $(x, z) \in R),[x]_{R}=$ $\{y \mid(x, y) \in R\} \quad$ is the equivalence class of $\mathrm{R}$, $U / R=\left\{[x]_{R} \mid x \in U\right\}$, and $(\mathrm{U}, \mathrm{R})$ is called an approximation space.

Definition 2.1 Let $U$ be a finite universe, $(U, R)$ be an approximation space, $A \in F(U)$,

If $\underline{R}(A)=\bar{R}(A)=A$, then $\mathrm{A}$ is called $\mathrm{R}$ crisp set; Otherwise, $\mathrm{A}$ is called $\mathrm{R}$ rough fuzzy set, and $\mathrm{R}(\mathrm{A})$ is called $\mathrm{R}$ lower approximation for $\mathrm{A}, \mathrm{R}(\mathrm{A})$ is called the $\mathrm{R}$ upper approximation for $\mathrm{A}$, and

$$
\rho_{R}(A)=1-\frac{|\underline{R}(A)|}{|\bar{R}(A)|}
$$

is called $\mathrm{R}$ fuzzy roughness of A. Among them, $|A|=\sum_{x \in U} A(x)$

It is not difficult to see that (2) is an uncertainty measure involving fuzziness and roughness. But it is worth noting that this mode is only general considered the elements of A degree of compliance, without considering the role of different characteristics of different membership status in the decision-making process. Following we will further analyze the model (2) with a specific example.

Example 2.1 How to develop good habits to maintain good health problems in today's society is a widespread concern. In order to further explore the link between the living habits and health characteristics, an institution chooses 9 people about 65 years old with more comprehensive health information as the sample $U=\{x 1$, $\mathrm{x} 2, \ldots, \mathrm{x} 9\}$ to get a comprehensive analysis. Its results are shown in Table 1. Here: 1) U/R means the different division of $\mathrm{U}$ that with the different habits of the formation (x1,x2mean long term adherence to outdoor sports; $\mathrm{x} 3, \mathrm{x} 4$, $\mathrm{x} 5$ mean no fixed sports items with a more regular diet and living; $x 6, x 7, x 8, x 9$ mean no fixed movement and the law of life); 2) d1 and d2are two kinds of quantitative indicators that reflect whether the elements in U are healthy (d1 shows mental health, $\mathrm{d} 2$ shows organ health).

TABLE 1. 9 HEALTH INFORMATION INVESTIGATOR OBJECTS

\begin{tabular}{llllllllll}
\hline $\mathrm{U} / \mathrm{R}$ & \multicolumn{2}{c}{$\mathrm{X}_{1}$} & \multicolumn{3}{c}{$\mathrm{X}_{2}$} & \multicolumn{5}{c}{$\mathrm{X}_{3}$} \\
\hline $\mathrm{U}$ & $x_{1}$ & $X_{2}$ & $X_{3}$ & $X_{4}$ & $X_{5}$ & $X_{6}$ & $X_{7}$ & $X_{8}$ & $X_{9}$ \\
\hline$d_{1}$ & 0.8 & 0.8 & 0.9 & 0.9 & 0.9 & 0.1 & 0.7 & 0.7 & 0.7 \\
\hline$d_{2}$ & 0.8 & 0.8 & 0.9 & 0.9 & 0.9 & 0.1 & 0.1 & 0.6 & 0.7 \\
\hline
\end{tabular}

Since $\mathrm{d} 1$ and $\mathrm{d} 2$ can be considered as a fuzzy set on $\mathrm{U}$, and it can be used as a standard to reflect the correlation characteristics of living habits and health. Therefore, $\mathrm{d} 1$ and $\mathrm{d} 2$ are important indicator in describing the related features between habits and physical health. Easily to see that the difference between $\mathrm{d} 1$ and $\mathrm{d} 2$ is the membership degree of $\mathrm{x} 7$. Since the membership degree of $\mathrm{x} 6$ that belong to $\mathrm{d} 1$ and $\mathrm{d} 2$ is low, if we don't consider the $\mathrm{x} 6$, $\mathrm{d} 1$ can fully expressed by $\mathrm{U} / \mathrm{R}$, but $\mathrm{d} 2$ can't. Therefore, in terms of visual facts, the extent of $\mathrm{d} 1$ available to the $\mathrm{U} / \mathrm{R}$ is higher than $\mathrm{d} 2$ (that is, the roughness of dlexpressed by $U / R$ should be lower than that of $\mathrm{d} 2$ ). But if using (2) as the roughness measurement mode, the roughness is $\rho_{R}\left(D_{1}\right)=\rho_{R}\left(D_{2}\right)=2.4$. The main reason is that (2) didn't consider the state of role, and the problem precisely reflects the essential characteristics of fuzzy decision. This shows construct a rough measure that contains fuzzy awareness process has important theoretical and practical value.

\section{THE FunCtion ChARACTERISTICS OF MEMBERSHIP DEGREE IN DECISION-MAKING}

Under fuzzy environment, the level of the decision requirement satisfaction is must to be faced when we make decision. The greater satisfaction level is, the higher reliability of decision-making based on the scheme is. But it is worth noting that the function with different membership state in the decision-making process often doesn't have a linear relationship. In the following we will analyze the function characteristics of membership degree in decisionmaking combined with a specific example.

Problem description: One company undertakes a comprehensive major project which is consisted by five subprojects. In order to successfully complete the project, the company sets up five working teams for five sub-projects combined with previous work performance. Completed profits of each sub-project and working capacity of each team are shown in Table 1. Where, ai represents standard income value of the $\mathrm{i}$-th sub-project (unit: ten thousand yuan), bi represents the ability of the i-th teach for completing the sub-project in the ideal period, namely the level of trust, and cil, ci2and ci3 separately express the yield of the i-th sub-project have been completed in the first, second and third period. Then we try to estimate the total revenue of the project.

$$
\underline{R}(A)(x)=\inf \left\{A(y) \mid y \in[x]_{R}\right\}, \bar{R}(A)(x)=\sup \left\{A(y) \mid y \in[x]_{R}\right\} .
$$

TABLE 2. The EARNINGS OF EACH COMPLETED SUB-PROJECT

\begin{tabular}{cccccc}
\hline$i$ & 1 & 2 & 3 & 4 & 5 \\
\hline$a_{i}$ & 100 & 130 & 125 & 86 & 142 \\
\hline$b_{i}$ & 1 & 0.8 & 0.7 & 1 & 0.75 \\
\hline$\left(c_{\mathrm{i} 1}, c_{\mathrm{i} 2}, c_{i 3}\right)$ & $(1,0.8,0.6)$ & $(1,0.8,0.6)$ & $(1,0.8,0.5)$ & $(1,0.85,0.86)$ & $(1,0.7,0.55)$ \\
\hline
\end{tabular}


While the work ability belongs to the fuzzy concept, different people have different understanding on it. So $\mathrm{B}=(\mathrm{b} 1, \mathrm{~b} 2, \mathrm{~b} 3, \mathrm{~b} 4, \mathrm{~b} 5)=(1,0.8,0.7,1,0.75)$ can be considered as a fuzzy set on $U=\{1,2,3,4,5\}$, and the estimates of the total revenue is a fuzzy decision problem. According to the concept of fuzzy sets, we know $\mathrm{Bi}=\mathrm{bi}=1$ represents that the i-th team absolutely have the ability to accomplish the i-th sub-project, and $\mathrm{Bi}=$ bi $<1$ represents that the $\mathrm{i}$-th team doesn't have the ability to accomplish the i-th sub-project. Finally, the issue of the specific complete time is the core to estimate the total revenue. According to the above analysis and date given, Table 3 gives the estimation results of the four managers of each sub-project completion period.

TABLE 3. THE ESTIMATION RESULTS OF THE FOUR MANAGERS OF EACH SUB-PROJECT COMPLETION PERIOD

\begin{tabular}{lccccc}
\hline & 1 & 2 & 3 & 4 & 5 \\
\hline \multirow{2}{*}{ manager1 } & $\begin{array}{c}\text { First } \\
\text { period }\end{array}$ & $\begin{array}{c}\text { First } \\
\text { period }\end{array}$ & $\begin{array}{c}\text { Second } \\
\text { period }\end{array}$ & $\begin{array}{c}\text { First } \\
\text { period }\end{array}$ & $\begin{array}{c}\text { Second } \\
\text { period }\end{array}$ \\
\hline \multirow{2}{*}{ manager2 } & $\begin{array}{c}\text { First } \\
\text { period }\end{array}$ & $\begin{array}{c}\text { Second } \\
\text { period }\end{array}$ & $\begin{array}{c}\text { Second } \\
\text { period }\end{array}$ & $\begin{array}{c}\text { First } \\
\text { period }\end{array}$ & $\begin{array}{c}\text { Second } \\
\text { period }\end{array}$ \\
\hline \multirow{2}{*}{ manager3 } & First & Second & Second & First \\
period & period & period & period & Third period \\
\hline \multirow{2}{*}{ manager4 } & First & Second & Third & First \\
period & period & Third period & period & Thiod \\
\hline
\end{tabular}

From Table 3 we can see that the preference of different decision makers dealing with the fuzzy state is not same, but the function of the membership degree has always followed the following basic principles:

Principle 1: The action is invariant of crisp state;

Principle 2: The action is monotonic of membership degree.

If the processing mechanisms of membership degree satisfying all above principles can be abstracted as a function $\mathrm{S}(\mathrm{x})$ from $[0,1]$ to $[0,1]$ ( called membership effect function), then it should meet the following conditions. 1) Regularity, that is $\mathrm{S}(0)=0, \mathrm{~S}(1)=1$; 2) Monotonicity, that is $S(x) \leq S(y)$ for any $0 \leq x \leq y \leq 1$; 3$)$ Continuity, that is $\mathrm{S}(\mathrm{x})$ is continuous on $[0,1]$. It is easy to see that both

$$
S_{1}(x)=x^{n}
$$

And

$$
S_{2}(x)=\left\{\begin{array}{cl}
0, & x<\alpha \\
(x-\alpha) /(\beta-\alpha), & \alpha \leq x \leq \beta \\
1, & x>\beta
\end{array}\right.
$$

are membership effect functions (here, $n \geq 0$, $0 \leq \alpha<\beta \leq 1$ ). Because of different membership effect functions reflect the different fuzzy processing preference (For example, for $\mathrm{S}(\mathrm{x})=\mathrm{xn}$ with $\mathrm{n}>1$, although the effect values of different membership degree reduced, but reduced rate changes conversely with degree of membership). Therefore, we can select the appropriate membership effect function combined with the specific fuzzy processing preference in the practical problems.

\section{FuZZY Roughness MEASURE BASED ON MEM BERSHIP EFFECT (FRM-BME)}

For a fuzzy set A and membership effect function $\mathrm{S}(\mathrm{x})$, if we denote $S(A)$ as fuzzy set

$\mathrm{S}(\mathrm{A})(\mathrm{x})$ that based on membership function $\mathrm{S}(\mathrm{A}(\mathrm{x}))$, then we have

$$
\Phi(R, S(x), A)=\left\{\begin{array}{cl}
1-|\underline{R}(S(A))| /|\bar{R}(S(A))|, & S(A) \neq \varnothing \\
0, & S(A)=\varnothing
\end{array}\right.
$$

as a rough measure on $\mathrm{A}$ that based on membership effect function $\mathrm{S}(\mathrm{x})$ (referred to as

the effect based on membership roughness measure). In particular, when $\mathrm{S}(\mathrm{x})=\mathrm{x}$ the measure is the mode (2).

Theorem 4.1 Let $U$ be a finite universe, $R 1$ and $R 2$ be equivalence relations on $\mathrm{U}, \quad$ and $R_{2} \subseteq R_{1}$. Then $\Phi\left(R_{1}, S(x), A\right) \geq \Phi\left(R_{2}, S(x), A\right) \quad$ is permanently established for any membership effect function $\mathrm{S}(\mathrm{x})$ and $A \in F(U)$

Proof: It follows from $R_{2} \subseteq R_{1}$, that $[x]_{R_{2}} \subseteq[x]_{R_{1}}$, $\bar{R}_{1}(S(A))(x) \geq \bar{R}_{2}(S(A))(x) \quad, \quad \underline{R}_{1}(S(A))(x) \leq \underline{R}_{2}(S(A))(x) \quad$ is permanently establish for any $x \in U$. Thus $\left|\bar{R}_{1}(S(A))\right| \leq$ $\left|\bar{R}_{2}(S(A))\right| \quad\left|\underline{R}_{1}(S(A))\right| \geq\left|\underline{R}_{2}(S(A))\right|$ $\left|\underline{R}_{1}(S(A))\right| /\left|\bar{R}_{1}(S(A))\right| \triangleleft\left|\underline{R}_{2}(S(A))\right| /\left|\bar{R}_{2}(S(A))\right|$ ,ie. $\Phi\left(R_{1}, S(x), A\right) \geq \Phi\left(R_{2}, S(x), A\right)$

Theorem 4.2 Let $U$ be a finite universe, $R$ be an equivalence relation on $\mathrm{U}$, and $A \in F(U)$. Then for any membership effect function $\mathrm{S}(\mathrm{x}), \Phi(R, S(x), A)=0$ if and only if that $\mathrm{A}$ is the crisp set of $\mathrm{R}$.

Proof : Sufficiency is obvious, then we considering the necessity. Assume that A isn't the crisp set of $\mathrm{R}$. This implies that there is $x_{0} \in U$ such that $\left|\left[x_{0}\right]_{R}\right| \geq 2$, and $\max \left\{A(x) \mid x \in\left[x_{0}\right]_{R}\right\}>\min \left\{A(x) \mid x \in\left[x_{0}\right]_{R}\right\}$. It follows that the inequation $\bar{R}(A)(x)>\quad \underline{R}(A)(x)$ is permanently established for any $x \in\left[x_{0}\right]_{R},|\bar{R}(A)|>|\underline{R}(A)|, 0 \leq|\underline{R}(A)| /$ $|\bar{R}(A)|<1, \rho_{R}(A)>0$. (ie. $\Phi(R, S(x), A)>0$ if $\left.\mathrm{S}(\mathrm{x})=\mathrm{x}\right)$. This is a contradiction with $\Phi(R, S(x), A)=0$ is permanently established for any $\mathrm{S}(\mathrm{x})$.

Theorem 4.3 Let $\mathrm{U}$ be a finite universe, and $\mathrm{R}$ be an equivalence relation on $\mathrm{U}$. Then for any membership effect functions $\mathrm{S} 1(\mathrm{x})$ and $\mathrm{S} 2(\mathrm{x}), \Phi\left(R, S_{1}(x), A\right)=\Phi\left(R, S_{2}(x), A\right)$ if and only if that $A \in \mathscr{P}(U)$.

Proof: The sufficiency is permanently established because of $S(A)=A$ is permanently established for any 
membership effect function $\mathrm{S}(\mathrm{x})$ and $A \in \mathscr{P}(U)$. Then consider the necessity. Assume that $A \notin \mathscr{P}(U)$. This implies that there is $X_{k} \in U / R=\left\{X_{1}, X_{2}, \cdots, X_{m}\right\}$ and $y \in X_{k}$ such that $0<\mathrm{A}(\mathrm{y})<1$ and $\min \left\{A(x) \mid x \in X_{k}\right\}<\max \{A(x) \mid$ $\left.x \in X_{k}\right\}$ (Let's assume that $X_{k} \in U / R$ is establishment under any conditions). Note that $\alpha=\min \{A(x) \mid x \in U$ and $A(x)>0\}$, then for membership effect functions $\mathrm{S} 1(\mathrm{x})=\mathrm{x}$ and $\mathrm{S} 2(\mathrm{x})$ :

$$
S_{2}(x)=\left\{\begin{array}{cc}
0, & 0 \leq x \leq \alpha \\
(x-\alpha) /(1-\alpha), & \alpha<x \leq 1
\end{array}\right.
$$

$$
\begin{aligned}
& \text { we have }\left|\bar{R}\left(S_{1}(A)\right)\right|=\left|\bar{R}\left(S_{2}(A)\right)\right|=|\bar{R}(A)| \text {, } \\
& \left|\underline{R}\left(S_{1}(A)\right)\right|<|\underline{R}(A)|=\left|\underline{R}\left(S_{2}(A)\right)\right| \text {. By this we have }
\end{aligned}
$$
$\Phi\left(R, S_{1}(x), A\right)>\Phi\left(R, S_{2}(x), A\right)$. It is a contradictions with $\Phi\left(R, S_{1}(x), A\right)>\Phi\left(R, S_{2}(x), A\right)$ for any membership effect function $\mathrm{S} 1(\mathrm{x})$ and $\mathrm{S} 2(\mathrm{x})$.

The above discussions indicate that FRM-BME is a mode that contains fuzziness conscious process, not only is a promotion of Pawlak rough measure, but also has good interpretative and structural characteristics, which embodies as: 1) The thinner division between $\mathrm{R}$ is, the smaller roughness will be (ie, the stronger description ability of ( $U$, R) will be); 2) The membership effect operator can play a role only on the condition that the object to be measured have fuzziness and roughness at the same time.

\section{V.THE APPLICATION OF FuZZy Roughness MEASUREMENT MODEL IN THE FUZZY DECISION}

Uncertainty is the basis of uncertain decision, it is unavoidable problem in the practical issue. We will further analyze the characteristics and effectiveness of FRM-BME combining with attribute reduction under fuzzy environment.

Problem description: In order to improve the management level, strengthen the guidance and service ability, a management authority have requested 60 subsidiary companies (referred to as $U=\left\{x_{1}, x_{2}, \mathrm{~L}, x_{60}\right\}$ ) to operate the investigation and data statistics. The results are shown in Table 4 (where a1 represents the size of company, its range is $\mathrm{V} 1=\{\operatorname{large}(1)$, medium (2), small (3) $\}$; a 2 represents net profit margin, its range is $\mathrm{V} 2=\{$ high (1), general (2), low (3)\}; a3 represents debt, its range is $\mathrm{V} 3=\{$ much (1), little $(2)\}$; a4 is the product quality, its range is $\mathrm{V} 4=\{$ excellent (1),good (2), general (3), bad (4) $\}$; the a5 represents ability of technology innovation, its range is V5 $=\{$ weak (1),strong (2) $\}$; a6 represents number of employees, its range is $\mathrm{V} 6=\{$ more (1), general (2), less (3) ; a7 is per capita wage, its range is $\mathrm{V} 7=\{$ high (1), low (2) $\}$; $\mathrm{d}$ represents the company's comprehensive performance evaluation, the ranges is $\mathrm{Vd}=[0,1])$. Try to find the main factors in determining what influence the comprehensive performance. 
TABLE 4. 60 COMPANY-RELATED BUSINESS INFORMATION

\begin{tabular}{|c|c|c|c|c|c|c|c|c|c|c|c|c|c|c|c|}
\hline & $x_{1}$ & $x_{2}$ & $x_{3}$ & $x_{4}$ & $x_{5}$ & $x_{6}$ & $x_{7}$ & $x_{8}$ & $x_{9}$ & $x_{10}$ & $x_{11}$ & $x_{12}$ & $x_{13}$ & $x_{14}$ & $x_{15}$ \\
\hline$a_{1}$ & 1 & 1 & 1 & 1 & 1 & 1 & 1 & 1 & 1 & 1 & 1 & 1 & 1 & 1 & 1 \\
\hline$a_{2}$ & 1 & 1 & 1 & 1 & 1 & 2 & 2 & 2 & 2 & 2 & 2 & 2 & 2 & 2 & 2 \\
\hline$a_{3}$ & 2 & 2 & 2 & 2 & 2 & 1 & 1 & 1 & 1 & 1 & 1 & 1 & 1 & 1 & 1 \\
\hline$a_{4}$ & 1 & 1 & 1 & 1 & 1 & 1 & 1 & 1 & 1 & 1 & 1 & 4 & 4 & 4 & 4 \\
\hline$a_{5}$ & 1 & 1 & 1 & 1 & 1 & 1 & 1 & 1 & 1 & 1 & 1 & 1 & 1 & 1 & 1 \\
\hline$a_{6}$ & 1 & 1 & 1 & 1 & 1 & 1 & 1 & 1 & 1 & 1 & 1 & 2 & 2 & 2 & 2 \\
\hline$a_{7}$ & 1 & 1 & 1 & 1 & 1 & 1 & 1 & 1 & 1 & 1 & 1 & 2 & 2 & 2 & 2 \\
\hline \multirow[t]{2}{*}{$d$} & 1 & 0.9 & 0.9 & 1 & 0.7 & 0.8 & 0.7 & 0.8 & 0.7 & 0.7 & 0.7 & 0.3 & 0.4 & 0.6 & 0.7 \\
\hline & $x_{16}$ & $x_{17}$ & $x_{18}$ & $x_{19}$ & $x_{20}$ & $x_{21}$ & $x_{22}$ & $x_{23}$ & $x_{24}$ & $x_{25}$ & $x_{26}$ & $x_{27}$ & $x_{28}$ & $x_{29}$ & $x_{30}$ \\
\hline$a_{1}$ & 1 & 1 & 1 & 1 & 1 & 1 & 1 & 1 & 1 & 2 & 2 & 2 & 2 & 2 & 2 \\
\hline$a_{2}$ & 2 & 2 & 2 & 2 & 2 & 2 & 2 & 2 & 2 & 3 & 3 & 3 & 3 & 3 & 3 \\
\hline$a_{3}$ & 1 & 1 & 1 & 1 & 1 & 2 & 2 & 2 & 2 & 2 & 2 & 2 & 2 & 2 & 2 \\
\hline$a_{4}$ & 4 & 4 & 4 & 4 & 4 & 2 & 2 & 2 & 2 & 3 & 3 & 3 & 3 & 3 & 3 \\
\hline$a_{5}$ & 1 & 1 & 1 & 1 & 1 & 1 & 1 & 1 & 1 & 2 & 2 & 2 & 2 & 2 & 2 \\
\hline$a_{6}$ & 2 & 2 & 2 & 2 & 2 & 1 & 1 & 1 & 1 & 2 & 2 & 2 & 2 & 2 & 2 \\
\hline$a_{7}$ & 2 & 2 & 2 & 2 & 2 & 2 & 2 & 2 & 2 & 2 & 2 & 2 & 2 & 2 & 2 \\
\hline \multirow[t]{2}{*}{$d$} & 0.5 & 0.5 & 0.2 & 0.3 & 0.6 & 0.6 & 0.6 & 0.7 & 0.6 & 0.5 & 0.5 & 0.5 & 0.5 & 0.5 & 0.5 \\
\hline & $x_{31}$ & $x_{32}$ & $x_{33}$ & $x_{34}$ & $x_{35}$ & $x_{36}$ & $x_{37}$ & $x_{38}$ & $x_{39}$ & $x_{40}$ & $x_{41}$ & $x_{42}$ & $x_{43}$ & $x_{44}$ & $x_{45}$ \\
\hline$a_{1}$ & 2 & 3 & 3 & 3 & 3 & 2 & 2 & 2 & 2 & 2 & 2 & 2 & 2 & 2 & 3 \\
\hline$a_{2}$ & 3 & 1 & 1 & 1 & 1 & 2 & 2 & 2 & 2 & 2 & 2 & 2 & 2 & 2 & 1 \\
\hline$a_{3}$ & 2 & 1 & 1 & 1 & 1 & 2 & 2 & 2 & 2 & 2 & 2 & 2 & 2 & 2 & 2 \\
\hline$a_{4}$ & 3 & 3 & 3 & 3 & 3 & 4 & 4 & 4 & 4 & 4 & 4 & 4 & 4 & 4 & 3 \\
\hline$a_{5}$ & 2 & 1 & 1 & 1 & 1 & 1 & 1 & 1 & 1 & 1 & 1 & 1 & 1 & 1 & 1 \\
\hline$a_{6}$ & 2 & 2 & 2 & 2 & 2 & 3 & 3 & 3 & 3 & 3 & 3 & 3 & 3 & 3 & 2 \\
\hline$a_{7}$ & 2 & 1 & 1 & 1 & 1 & 2 & 2 & 2 & 2 & 2 & 2 & 2 & 2 & 2 & 2 \\
\hline \multirow[t]{2}{*}{$d$} & 0.5 & 0.8 & 0.8 & 0.7 & 09 & 0.6 & 0.6 & 0.6 & 0.7 & 0.5 & 0.6 & 0.5 & 0.4 & 0.7 & 0.8 \\
\hline & $x_{46}$ & $x_{47}$ & $x_{48}$ & $x_{49}$ & $x_{50}$ & $x_{51}$ & $x_{52}$ & $x_{53}$ & $x_{54}$ & $x_{55}$ & $x_{56}$ & $x_{57}$ & $x_{58}$ & $x_{59}$ & $x_{60}$ \\
\hline$\overline{a_{1}}$ & 3 & 3 & 3 & 3 & 3 & 3 & 3 & 3 & 3 & 3 & 3 & 2 & 2 & 2 & 2 \\
\hline$a_{2}$ & 1 & 1 & 1 & 2 & 2 & 2 & 2 & 2 & 3 & 3 & 3 & 3 & 3 & 3 & 3 \\
\hline$a_{3}$ & 2 & 2 & 2 & 2 & 2 & 2 & 2 & 2 & 2 & 2 & 2 & 1 & 1 & 1 & 1 \\
\hline$a_{4}$ & 3 & 3 & 3 & 2 & 2 & 2 & 2 & 2 & 3 & 3 & 3 & 3 & 3 & 3 & 3 \\
\hline$a_{5}$ & 1 & 1 & 1 & 2 & 2 & 2 & 2 & 2 & 1 & 1 & 1 & 3 & 3 & 3 & 3 \\
\hline$a_{6}$ & 2 & 2 & 2 & 1 & 1 & 1 & 1 & 1 & 3 & 3 & 3 & 3 & 3 & 3 & 3 \\
\hline$a_{7}$ & 2 & 2 & 2 & 2 & 2 & 2 & 2 & 2 & 1 & 1 & 1 & 2 & 2 & 2 & 2 \\
\hline$d$ & 0.9 & 0.9 & 0.8 & 0.5 & 0.5 & 0.5 & 0.6 & 0.4 & 0.6 & 0.6 & 0.7 & 0.1 & 0.1 & 0.2 & 0.2 \\
\hline
\end{tabular}

If we regard $A=\{a 1, a 2, a 3, a 4, a 5, a 6, a 7\}$ as the condition attribute sets, $\mathrm{d}$ as decision attribute, then Table 4 can be considered as a decision table. Therefore, according to whether the value of each property in B is same or not, we can use $\mathrm{RB}$ to indicates an equivalence relation on $\mathrm{U}$ with $B \subset A$. Then the main factors influencing the selection comprehensive operating performance can be expressed as: we should indicate to make sure note (U, RA) and (U, RB) are same in the description ability of $d$. Since $d$ can be considered a fuzzy set on $U$ and values of the condition attribute are fuzzy terms. Therefore, if we use $\Phi\left(R_{B}, S(x), d\right)$ as measurement model of (U, RA) to describe $\mathrm{d}$, thus the main factors affecting the selection of comprehensive operating performance can be further described like this, we can define $B \subset A$ to meet $\Phi\left(R_{B}, S(x), d\right)=\Phi\left(R_{A}, S(x), d\right)$. Table 5 provides several different membership effect functions corresponding to the reduction results. 
TABLE 5. SEVERAL DifFerent MEMBERShiP EFFECT FunCtions CORRESPONDING to the REDUCTION RESUlts

\begin{tabular}{|c|c|c|c|c|}
\hline \multicolumn{3}{|c|}{ membership effect function $S(x)$} & $\Phi\left(R_{A}, S(x), d\right)$ & reduction results $B$ \\
\hline \multirow{2}{*}{\multicolumn{2}{|c|}{$S_{1}(x)=x^{n}$}} & $n=0.5$ & 11 & $\left\{a_{1}, a_{2}, a_{4}, a_{5}, a_{7}\right\}$ \\
\hline & & $n=1$ & 18.54 & $\left\{a_{1}, a_{2}, a_{4}, a_{5}, a_{7}\right\}$ \\
\hline \multirow{3}{*}{$S_{2}(x)=\{$} & 0 & $x_{\alpha} \leqslant \alpha .5, \beta=1$ & 34.5 & $\left\{a_{1}, a_{2}, a_{4}, a_{7}\right\}$ \\
\hline & $(x-a) /(\beta-\alpha)$, & $\alpha \leq x \leq \beta$ & & \\
\hline & 1, & $\alpha x \Rightarrow 0 \beta, \beta=0.7$ & 26.58 & $\left\{a_{1}, a_{4}\right\}$ \\
\hline
\end{tabular}

Table 5 shows that: the effect determined by different membership effect function is different, even the difference is big. Especially for $\mathrm{S} 1(\mathrm{x})$ with $\mathrm{n}=1$ equivalent to formula (2). But the formula (2) does not consider the influence of the effect of membership. Fuzzy roughness measurement model based on membership effect, the advantage of this model is that it can freely choose the membership effect function, at the same time it can integrate the fuzzy processing preference into roughness measurement system. Due to different problems have different fuzziness processing, it should be combined with specific systematically requirements to choose membership effect functions in practical problems.

\section{CONCLUSIONS}

Considering the shortcomings of the current uncertainty measurement algorithm of rough fuzzy set, this paper introduces the concept of membership effect function, establishes the fuzzy roughness measurement base on membership effect, and use case studies to analyze the specific features and effectiveness of FRM-BME. Theoretical and experimental results show that FRM-BME not only has good structural characteristics, but also succinctly to deal with the fuzziness preference into the decision-making process. Therefore, to a certain extent, this discussion not only enriches rough set theory and fuzzy set theory, but also has significance in application such as complex environments, artificial intelligence, resource management, information security. But it is worth noting that we can also do the sample space reduction, we think the low degree of membership data as noise data to the sample space, and this datum can be deleted. This can help us to combine the membership status with decision process. And this will be the main content of our future work.

\section{ACKNOWLEDGMENTS}

This work is supported by the National Natural Science Foundation of China $(71540001,71371064)$ and the Natural Science Foundation of Hebei Province (F2015208099, F2015208100).

\section{REFERENCES}

[1] Pawlak, Z.: Rough Sets. International Journal of Information and Computer Science. 11, 341--356 (1982)

[2] Slowinski, R., Vanderpooten, D.: Fuzzy Similarity Relation as a Basis for Rough Approximations. Proceedings of the Second Annual Joint Conference on Information Sciences. 53, 249--250 (1995)

[3] Dai, J. H., Tian, H. W.: Fuzzy rough set model for set-valued data. Fuzzy Sets and Systems. 229, 54--68 (2013)

[4] Qian, Y. H., Wang, Q.: Fuzzy-rough feature selection accelerator. Fuzzy Sets and Systems. 258, 61--78 (2015)

[5] Jia, X. Y., Shang, L.: Generalized attribute reduct in rough set theory. Knowledge-Based Systems. 91, 204--218 (2016)

[6] Shu, W. H., Shen, H.: Incremental feature selection based on rough set in dynamic incomplete data. Pattern Recognition. 47, 3890--3906 (2014)

[7] Li, F. C., Zhang, Z., Jin, Ch. X.: A study of comprehensive evaluation method based on neighborhood covering information system. ICIC Express Letters, Part B: Applications. 4, 595--602 (2013)

[8] Parthalain, N. M., Richard, J.: Unsupervised fuzzy-rough set-based dimensionality reduction. Information Sciences. 229, 106--121 (2013)

[9] Yang, B., Hu, B. Q.: A fuzzy covering-based rough set model and its generalization over fuzzy lattice. Information Sciences. 367-368, 463$-486(2016)$ 